\title{
Improved Thermal Transmittance Measurement with HFM Technique on Building Envelopes in the Mediterranean Area
}

\author{
Patrizia Aversa $^{a}$, Antonio Donatelli ${ }^{a}$, Giuseppe Piccoli ${ }^{b}$, Vincenza Anna Maria Luprano ${ }^{a}$

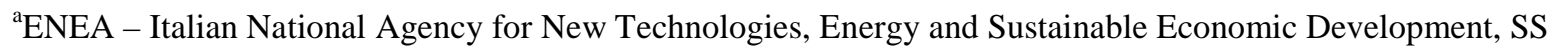 \\ Appia 7, km 706.00, 72100 Brindisi, Italy. \\ bInnovasystem Srl., Corso Racconigi, 180/6, 10141 Torino, Italy. \\ e-mail: patrizia.aversa@enea.it, antonio.donatelli@enea.it, direzione@innovasystem.it, \\ vincenza.luprano@enea.it
}

\begin{abstract}
Although the designed theoretical value of $U$ can be derived from the thermal parameters of layers composing an opaque element, according to ISO 6946:2007, measurements are necessary to confirm the expected behaviour. Currently, the measurements of thermal transmittance based on Heat Flow Meter method (HFM) and according to standard ISO 9869-1:2014 are widely accepted. Anyway, some issues related to difficulties in measurements are present: the roughness of wall surfaces, the proper contact between the heat flow plate and the temperature probes with wall surfaces, undesired changes in weather conditions. This work presents the results obtained in thermal transmittance measurements with a modified HFM method, widely described in this paper. Differences between U-values obtained with the modified HFM method and theoretical ones were in the range $0.6-6.5 \%$. Moreover, the modified HFM method provided a result closer to the theoretical one, when compared to that obtained with standard HFM method (discrepancy with theoretical value were $0.6 \%$ and $16.4 \%$, respectively).
\end{abstract}

Key words: thermal transmittance, heat flow meter, opaque element, buildings.

\section{Introduction}

Since several years, problems related to climate change and the causes that generate it are treated with special attention, because of the negative consequences it entails on nature and people. The problem has spread worldwide and therefore is dutifully treated by many nations. In particular, The United Nations Framework Convention on Climate Change (UNFCCC) composed by 19 Countries (December 2015), was founded with the aim to stabilize greenhouse gas concentrations in the atmosphere at a level that would prevent dangerous anthropogenic interference with the climate system. The last conference held by the UNFCCC was the "2015 United Nations Climate Change Conference" (COP 21), held in Paris, France, from November 30th to December 12th 2015, where Countries agreed, by consensus, to the final global pact (the Paris Agreement) to reduce emissions as part of the method for reducing GreenHouse Gases (GHG). Moreover, the members agreed to reduce their carbon "as soon as possible" and to do their best to keep global warming "to well below 2 degrees $\mathrm{C}$ ". 
In this framework, a great positive impact can be obtained by acting properly on buildings. As a matter of fact, buildings use about $40 \%$ of global energy, $25 \%$ of global water, $40 \%$ of global resources, and they emit approximately $1 / 3$ of GHG emissions. Residential and commercial buildings consume approximately $60 \%$ of the world's electricity and the building sector is the largest contributor to global GHG emissions. Yet, buildings also offer the greatest potential for achieving significant GHG emission reductions, at least cost, in developed and developing countries.

One important aspect on which one can adopt solutions in order to reduce energy in buildings is the thermal behaviour of wall, expressed by its thermal transmittance U, which describes the ability of wall of opposing to heat-flux: the lower the thermal transmittance, the greater this opposition. Thermal transmittance of wall can be estimated if its stratigraphy and the thermal parameters of layers which compose it (basically thicknesses and thermal conductivities) are known, according to standard ISO 6946:2007 [1] which assumes conditions that often diverge from reality: uniformity of layers, proper installation, no irregularities within the cross-section. To these factors, the natural obsolescence of the walls must be added, which inevitably leads to reduce the performance over time. For these reasons, experimental measurements of thermal transmittances are mandatory for a proper evaluation of thermal behaviour of walls.

Currently, the experimental measurements of the thermal transmittance based on heat flow meter (HFM) and according to standard ISO 9869-1:2014 [2] are widely accepted. It is based on a continuous and protracted for several days measurement of heat-flux and surface temperatures of opaque elements [3-7]. Several works relate to effectiveness of HFM method technique and address the issues raised. Asdrubali et al. [6] performed a measurement campaign of in situ thermal transmittances in Umbria Region (Italy) and highlighted that measurements and theoretical U-values were not in perfect agreement, in particular for walls without insulating materials. In all the cases the differences were not less than $14 \%$. Ahmad et al [7] also investigated the thermal transmittances of buildings in according to ISO 98691:2014, highlighting that wall orientation and the outside weather conditions affect the results. Peng and $\mathrm{Wu}$ [8] applied HFM technique on a building in Nanjing, comparing three different designed methods to evaluate the thermal insulation of the test chamber. Differences between measured and designed U-values were in the range 2-24\%. Generally, comparison between Uvalues resulting from HFM and designed ones shows differences up to $16 \%$ [3, 9-12].

Even if we strictly adhere to the approach described by the reference standards, the HFM method presents some uncertainties. It is evident that the calculated values could be affected from temperatures and heat-flux measurement: Meng et al. [13] studied which factors affect the in situ measurement of $U$ when the HFM method is applied. They found that thermocouples and heat flow meter locations, as well as pasting angle, size and shape of heat flow meter affect the measurement at different extent. In particular, the mortar joints must be avoided as location for the thermocouples. Desogus et al. [12] highlighted that measurement via HFM method could be affected by plastering of heat flow meter on the surface, because of changing in temperature fields around it.

In order to reduce the systematic errors in measurement, in our work we focused the attention on some aspects of the HFM method that could be improved. In particular, first a preliminary investigation of different opaque envelopes and with a thermal camera, in accordance with standard ISO 6781:1983 [14] was performed, in order to individuate the most appropriate area for the measurement of thermal transmittance. Then a slightly modified HFM method, based 
on a multiple measurement of wall temperatures and on an improved adhesion between the temperature probes and the wall surface, was applied. The accuracy of the proposed method and results obtained were evaluated by direct comparison with standard HFM method and with designed values obtained in according to standard ISO 6946:2007.

Another issue related to HFM method is that ISO 9869:1-2014 requires a long measurement time period, in order to remove uncertainties of measurements due to fluctuations in temperatures, mainly for walls exposed to outdoor where sunlight exposure or changings in weather conditions cannot be avoided. A general rule suggests that an acquisition time of at least 72 hours is sufficient, provided that the variations in the transmittance value measured in the last 24 hours are less than 5\% of the initial value of this interval (ISO 9869:1-2014).

The experimental campaign was performed in Apulia Region, in the south-east of Italy (Mediterranean Area), where high differences in temperatures between indoors and outdoors are not frequent. Anyway, ISO 9869:1-2014 states that heat flow meter measurement requires a difference of fifteen degree, or at least ten degree, between temperatures of internal and external sides of walls, therefore this condition has been ensured through forced conditioning (heating or cooling) of the internal rooms.

Conditioning of at least one side of vertical walls is important also related to the following issue: in terms of energy upgrading of buildings, the Apulia Region may provide that a feasibility study which includes the transmittance measurement of the vertical walls must be completed within 30 working days from the assignment of a contract. If within this period changings in weather conditions makes difficult the measurement, the feasibility study would be compromised. It is therefore necessary to get rid from this issue, through the possibility of performing measurements in a conditioned environment, or at least conditioning the inner side of the vertical wall.

\section{Materials and Apparatus}

Thermographic investigation of the opaque elements was performed with a thermal camera Flir T620 with uncooled microbolometer detector (image resolution $640 \times 680$ pixels, spectral range from 7.8 to $14 \mu \mathrm{m}$, thermal sensitivity less than $0.04{ }^{\circ} \mathrm{C}$, range of measurements from $40^{\circ} \mathrm{C}$ to $150{ }^{\circ} \mathrm{C}$ with an accuracy of $\pm 2{ }^{\circ} \mathrm{C}$ and picture frequency equal to $30 \mathrm{~Hz}$ ).

Heat flow meter (HFM) investigation was performed with apparatus according standard ISO 8301:1991 [15], provided by an Italian Company (Capetti Elettronica srl) and composed by:

- heat flow meter plate: diameter $50 \mathrm{~mm}$, thickness $5 \mathrm{~mm}$, sensitivity $50 \mu \mathrm{V} / \mathrm{m}^{2}$, accuracy $\pm 5 \%\left(@ \mathrm{~T}=20^{\circ} \mathrm{C}\right)$, temperature range from $-30^{\circ} \mathrm{C}$ to $+70^{\circ} \mathrm{C}$, thermal resistance of sensor less than $6.25 \cdot 10^{-3} \mathrm{~m}^{2} \mathrm{~K} / \mathrm{W}$, range from -2000 to $+2000 \mathrm{~W} / \mathrm{m}^{2}$;

- probe for temperature and humidity measurement: PT1000 class A with aluminum sensitive parts for better detection of the wall temperature, range of measurement from $-40^{\circ} \mathrm{C}$ to $80^{\circ} \mathrm{C}$, resolution $0.01^{\circ} \mathrm{C}$, accuracy $0.1^{\circ} \mathrm{C}$, range for relative humidity from 10 to $90 \%$;

- encapsulated probe for outdoor measurement of temperature and relative humidity: range of measurement from $-10^{\circ} \mathrm{C}$ to $60^{\circ} \mathrm{C}$, resolution $0.01^{\circ} \mathrm{C}$, accuracy $0.2{ }^{\circ} \mathrm{C}$, range for relative humidity from 0 to $90 \%$, resolution $0.05 \%$.

The measurements with the apparatus above described were compared with measurements performed with a standard HFM method and by a Company that provided the thermal insulation, which used the following instrumentations: 
- heat flow meter plate model ThermoZig Optivelox: range of power from -300 to +300 $\mathrm{Wm}^{2}$, resolution $0.01 \mathrm{Wm}^{-2}$, accuracy $\pm 5 \%\left(@ \mathrm{~T}=20^{\circ} \mathrm{C}\right)$, range of temperature from $20^{\circ} \mathrm{C}$ to $60{ }^{\circ} \mathrm{C}$, thermal resistance $0.006 \mathrm{~m}^{2} \mathrm{~K} / \mathrm{W}$.

- a probe for indoor temperature measurement: range of measurement from $-20^{\circ} \mathrm{C}$ to 60 ${ }^{\circ} \mathrm{C}$, positioned at $1.5 \mathrm{~m}$ above the floor (hang with a clip);

- a probe for outdoor temperature measurement: range of measurement from $-20^{\circ} \mathrm{C}$ to $60{ }^{\circ} \mathrm{C}$, positioned at $1.5 \mathrm{~m}$ above the floor (hang with a clip).

The experimental investigation was performed on some different opaque elements hereinafter listed.

- Case A: a partition wall of a Building hosting the Department of Engineering of the Politecnico di Bari (Italy), composed by a hollow brick $(30 \mathrm{~cm})$ plastered on both the sides $(1 \mathrm{~cm})$ and which separates two rooms with different climatic condition. The building is located in Bari, in Apulia Region, in the south-east of Italy: coordinates are $41^{\circ} 06^{\prime} 41^{\prime \prime} \mathrm{N}, 16^{\circ} 51^{\prime} 19^{\prime \prime} \mathrm{E}$. Bari is in the group Csa of Köppen climate classification (Mediterranean climates with Hot Summer) [16]. The city has a degree day of 1185 , calculated as in the Italian presidential Decree 412/93 and subsequent amendments and additions.

- Case B: a perimetral wall of a High school separates an internal room from external side. It is composed by (from internal to external): plaster $(2 \mathrm{~cm})$, tuff $(25 \mathrm{~cm})$, cavity wall $(6 \mathrm{~cm})$, tuff $(25 \mathrm{~cm})$, plaster $(2 \mathrm{~cm})$. The high school is in Mesagne, located in Apulia Region, in the south-east of Italy: coordinates are $40^{\circ} 34^{\prime} 0^{\prime \prime} \mathrm{N}, 17^{\circ} 48^{\prime} 0^{\prime \prime} \mathrm{E}$. Mesagne is in the group Csa of Köppen climate classification (Mediterranean climates with Hot Summer) [16]. The city has a degree day of 1237, calculated as in the Italian presidential Decree 412/93 and subsequent amendments and additions. The addition of an outer layer in rock wool (thickness of $10 \mathrm{~cm}$ ), type Frontrock max E, provided by Rockwool $^{\circledR}$ which declared a thermal conductivity of $0.036 \mathrm{~W} / \mathrm{mK}$ was applied on the outer surface of this perimetral wall, in order to improve its energy efficiency. Both the arrangements were studied, and hereinafter we will refer as Case B1 and Case B2 respectively for the wall without and with the thermal insulation layer.

The cross-section of investigated walls are clearly depicted in Fig. 1.

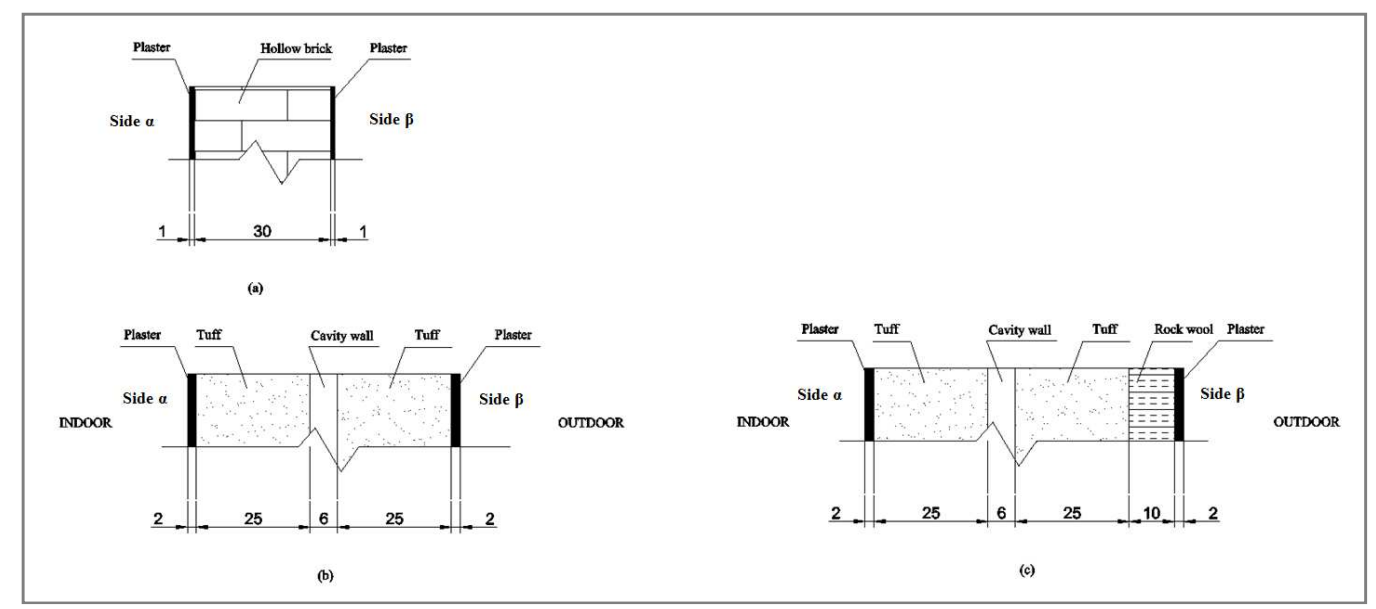

Figure 1: Cross-sections of investigated walls: Cases A (a), B1 (b) and B2 (c). 
It is worth to mention that all the rooms investigated were exposed on the north-west side but protected from direct solar radiation by means of near buildings. Moreover, all the windows in the investigated rooms were shielded by roller shutters in order to exclude the impact of solar gains or reduce the thermal dispersion through them.

All the rooms were kept empty and not frequented by students during the testing period.

Fig. 2 shows a map with position of Bari and Mesagne and Fig. 3 shows the expected trends in temperature and relative humidity $(\mathrm{RH})$ of air during a solar year, based on data recorded in Bari in the last 10 years obtained from ENEA archive [17]: the months are indicated with numbers from 1 to 12 ( 1 indicates January and 12 indicates December), the mean value is marked by a continuous line, while the minimum and maximum expected values are marked with dashed lines.

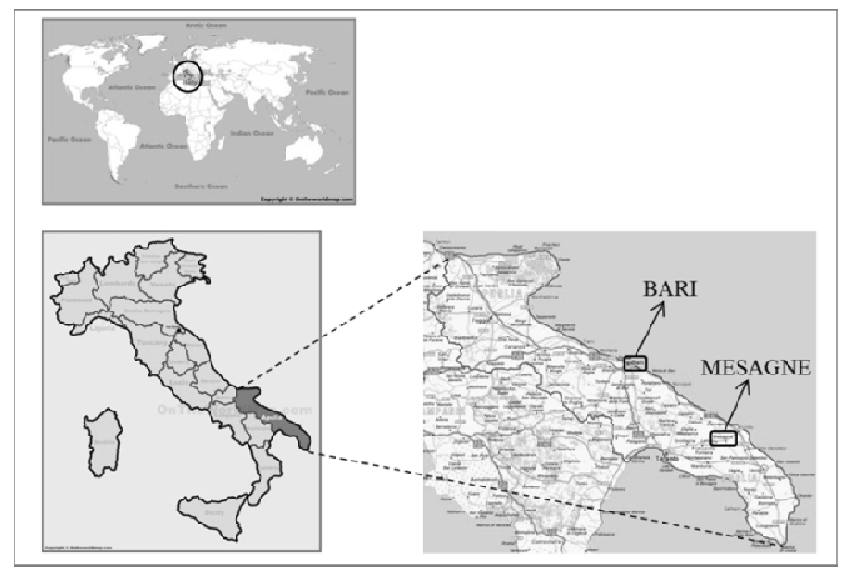

Figure 2: Geographical locations of investigated walls.

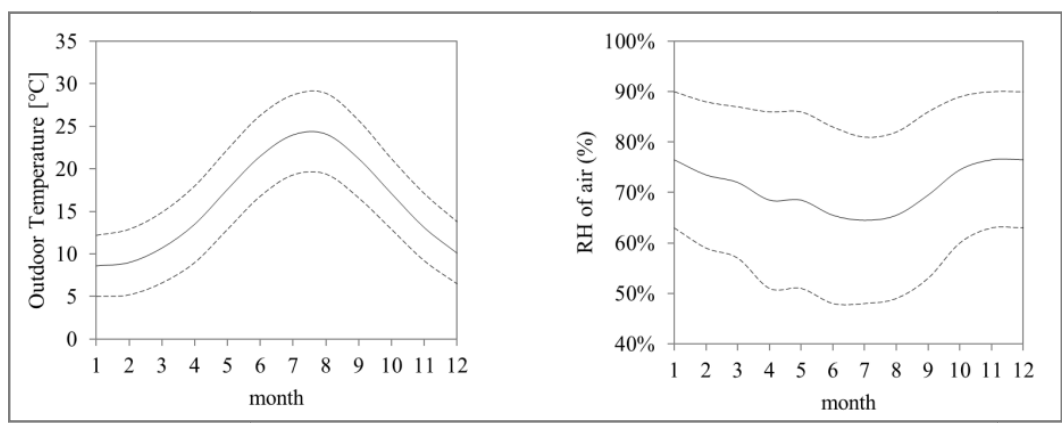

Figure 3: Yearly temperature and RH in air trends in Bari. Mean (continuous line) and expected maximum and minimum values (dashed lines).

\section{Methods}

For both the investigated walls, a preliminary investigation with the thermal camera Flir T620 and in accordance with standard ISO 6781:1983 allowed the individuation of the most appropriate area for the measurement of thermal transmittance by HFM method.

More in details, the wall surfaces was investigated by means of IR thermography with the purpose to verify the absence of thermal bridges or deteriorations of the plaster, or the 
presence of moisture by water infiltration in the opaque elements, in order to appropriately choose the area in which the measurement of transmittance would be performed. After the thermal conditioning, the wall presented thermal uniformity and the absence of thermal bridges: this situation has ensured that the wall was adequate to measurement.

The HFM method represents the most common and accepted method for measuring the thermal transmittance of opaque elements, according to the Standard ISO 9869-1:2014. It is based on monitoring and measuring of time variations of temperatures on both sides of an opaque element and of heat-flux passing through the wall. The state of art foresees the installation of the heat flow meter plate in the chosen point of the surface wall, for the measurement of the heat-flux through the cross section of the opaque element. Then a temperature probe is placed in contact with the surface, just few centimeters far from the heat flow meter plate. The contact between the temperature probe and the surface wall is generally not very meticulous: it is locked with the use of adhesive tape, or with a wall nail on which is hung. Our approach is different in some aspects (modified method):

i. the rooms separated by the wall for the case A, and the internal room for the cases B1 and B2, were conditioned (heated or cooled) for 48 hours in order to assure uniform and constant temperatures and a difference in temperatures between the sides of the wall not less than $10{ }^{\circ} \mathrm{C}$. Values of temperatures were different for the investigated cases and they are reported in section "Results".

ii. the most appropriate portion of the wall surface for the measurement of thermal transmittance was individuated by means of the thermographic investigation;

iii. In this area, a template in stiff cardboard (in Italian called DIMA) having an area of about $0.5 \mathrm{~m}^{2}$ (side of $0.7 \mathrm{~m}$ ) and including holes which allow to find the correct location of the temperature probes and the heat flow meter plate in a quick and precise way, was positioned. The DIMA was positioned in such a way that the heat flow meter plate was at $1.5 \mathrm{~m}$ far from the floor. The holes had different colors to help technicians in the proper individuation of the position of sensors on the inner and outer sides of the opaque wall (red and blue, respectively). DIMA allows the preservation of the relative positions of the sensors with respect to the heat flow plate, if manifold measurements are performed in different areas of the opaque wall (Fig. 4a).

iv. the DIMA was applied to the opaque wall with the aid of easily removable adhesive tape at the end of use. Then with a pencil the exact positions of the probes on both the inner and the outer walls were drawn (Fig. 4b). In particular, the heat flow meter plate was installed at the center of this square area, while the temperature probes were positioned at the vertices of a triangle, as shown in Fig. 4d. The same happens to the other side, where other three temperature probes were installed.

v. The contact between the temperature probe and the wall surface was improved in order to reduce undesired thermal resistance due to bad contact. More in detail, in the points chosen for the positioning of the temperature probes, the wall was coated with a commercial high thermal silicon grease, in order to reduce the surface roughness. Then the temperature probe, previously embedded in an envelope consisting of aluminum in the part of contact with the surface (because of its high thermal conductivity) and plastic in the outer part, was glued to the silicone. In addition, a layer of mastic surrounded the entire envelope, in order to reduce any lateral thermal dispersions (UHU ${ }^{\circledR}$ Patafix) (Fig. 4c).

This particular configuration was applied on all the investigated walls. 


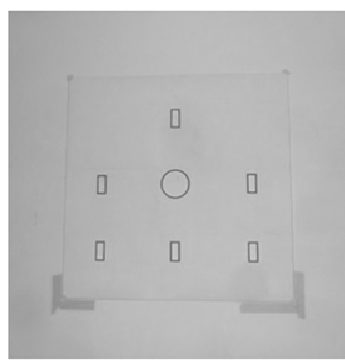

(a)

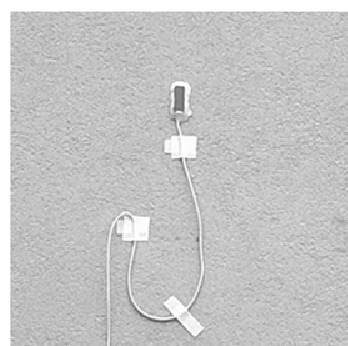

(c)

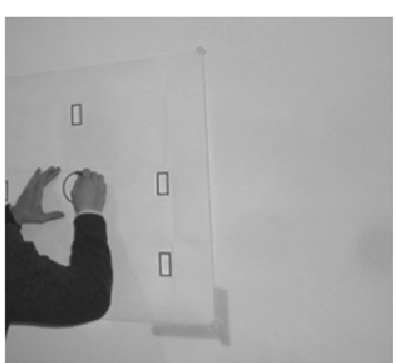

(b)

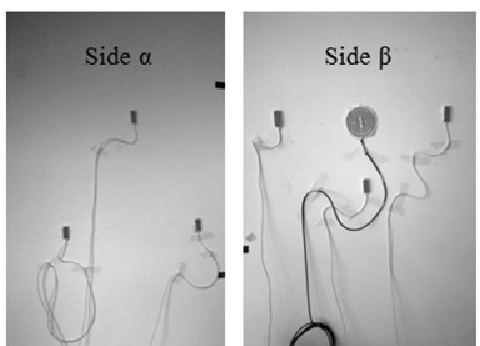

(d)

Figure 4: DIMA in modified HFM technique: template(a), marking of sensor positions (b), sensor adhesion on the wall (c) and final layout on both the sides (d).

The experimentation campaign aspired also to evaluate the effectiveness of the approach on walls placed in rooms strongly thermally conditioned; therefore, after conditioning of rooms, when done, the temperatures and heat-flux were monitored and recorded for three days and once the acquisition has been completed, an integral approach in measuring of thermal conductance was applied. In particular the thermal conductance $\Lambda$ was estimated as the mean value in the interval $\left[0, \mathrm{t}^{*}\right]$ :

$$
\Lambda=\frac{\int_{0}^{t^{*}} q(t) d t}{\int_{0}^{t^{*}}\left[T_{\alpha}(t)-T_{\beta}(t)\right] d t}
$$

where $\mathrm{T}_{\alpha}$ and $\mathrm{T}_{\beta}$ are the mean values of the three instantaneous temperature measurement obtained with the probes, on both the sides $\alpha$ and $\beta$, respectively.

Of course, the greater the interval between 0 and $\mathrm{t}^{*}$, the lower the uncertainty in the thermal conductance value. In all the cases $\mathrm{t}^{*}$ was at least three days.

Once the thermal conductance has been calculated, the thermal transmittance $U$ of the opaque element was calculated took in account the internal and external convection resistances $\left(1 / \mathrm{h}_{\mathrm{si}}\right.$ and $1 / \mathrm{h}_{\mathrm{se}}$ respectively):

$$
U=\frac{1}{\frac{1}{h_{s i}}+\frac{1}{\Lambda}+\frac{1}{h_{s e}}}
$$

Since measurements of temperatures and heat-flux are performed at regular intervals, the integral equation (1) is discretized assuming the form:

$$
\Lambda=\frac{\sum_{i=1}^{n} q_{i}}{\sum_{i=1}^{n}\left(T_{\alpha i}-T_{\beta i}\right)}
$$


in which $n$ is the number of temperatures and heat-flux measurements performed from $\mathrm{t}=0$ to $\mathrm{t}=\mathrm{t}^{*}$.

\section{Results}

For all the cases, measurements of temperatures wall on both the sides and heat-flux through the wall were continuously performed and registered. Fig. 5 shows the trends of temperatures and heat-flux registered. For the case A, measurements were performed in July and the rooms separated by the opaque element investigated were differently conditioned (heated and cooled respectively at $\mathrm{T}=37^{\circ} \mathrm{C}$ and $\mathrm{T}=26^{\circ} \mathrm{C}$ ), in order to assure a difference in temperature above $10^{\circ} \mathrm{C}$ as requested by the standard. For the case B1, measurements were performed in March when external temperatures were always less than $13{ }^{\circ} \mathrm{C}$, and internal room was heated to about $25{ }^{\circ} \mathrm{C}$, so also in this case a difference in temperature above $10{ }^{\circ} \mathrm{C}$ was assured. On the other hand, with regard to case B2, at certain times a difference between internal and external temperature greater than $10{ }^{\circ} \mathrm{C}$ was not satisfied, due to large oscillations in outdoor temperature; apart from the peak at time 48:30 (when the difference in temperature reached $7.1^{\circ} \mathrm{C}$ ), the difference in temperatures between the two sides of the room was not less than $9.1{ }^{\circ} \mathrm{C}$. In particular this is verified from 50:40 to the end of the measurement (91:40), therefore in the last 41 hours of the experimental campaign.

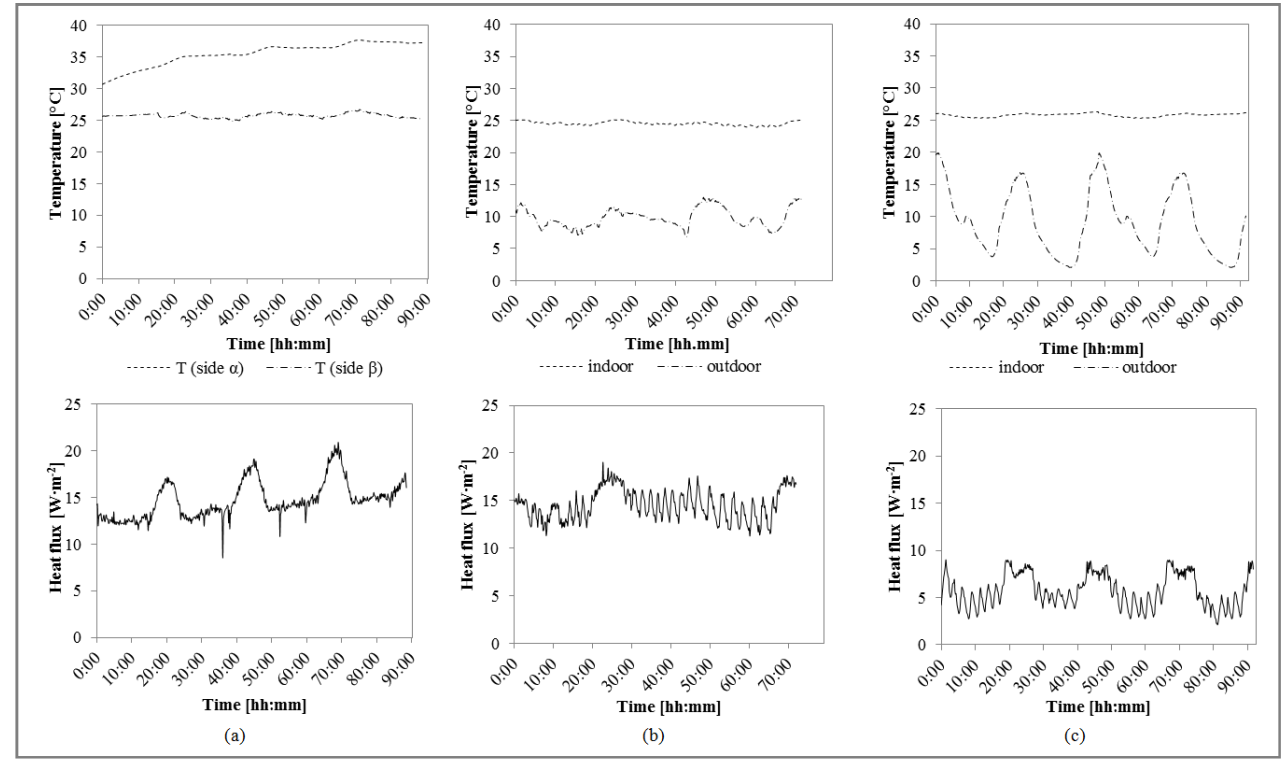

Figure 5: Temperatures and heat flows trends for Case A (a), B1 (b) and B2 (c).

Fig. 6 shows the thermal transmittance trend calculated in accordance with equation (2); it is evident that, in all the cases investigated, after several hours of measurement the thermal transmittance tends to a constant value. In particular, the amplitude of oscillations was calculated in the last 24 hours, according to equation:

$$
\Delta U(\%)=\frac{U_{\max }(t)-U_{\min }(t)}{U_{\text {in }}(t)}
$$


where $U_{\max }, U_{\min }$ and $U_{\text {in }}$ are respectively the maximum, minimum and initial values in the last 24 hours. They were $2.94 \%, 2.32 \%$ and $4.98 \%$ for Case $A, B 1$ and B2 respectively. Therefore, in all the cases they were less than 5\% as requested by ISO 9869-1:2014. In particular the thermal transmittance calculated for the case A can be considered acceptable despite the heat-flux in figure 5a seems to be increasing also at time 90:00 toward the steady state condition.

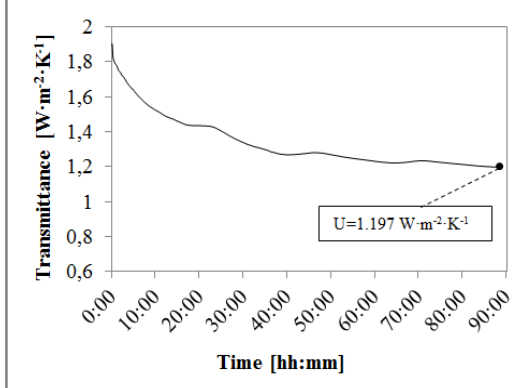

(a)

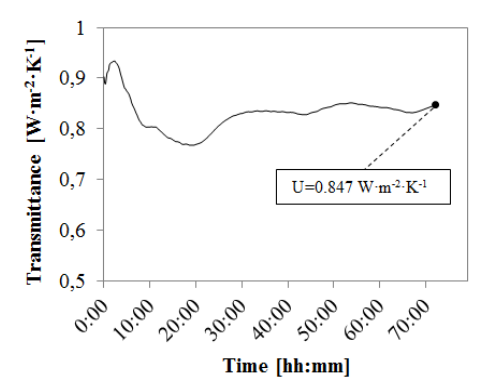

(b)

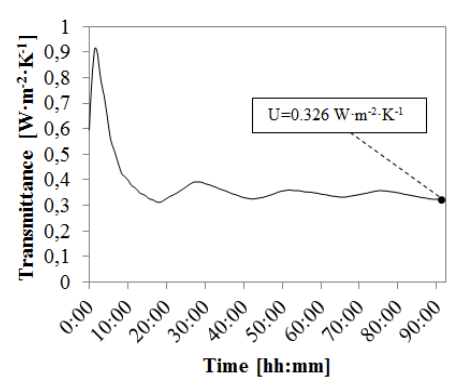

(c)

Figure 6: Thermal transmittances for Case A (a), B1 (b) and B2 (c).

The experimental results were then compared with the theoretical thermal transmittances calculated according to standard ISO 6946:2007, which applies to components and elements consisting of thermally homogeneous layers and is based on thermal conductivities or design thermal resistances of the materials and products for the application concerned. More in detail the theoretical thermal transmittance in accordance to ISO 6946:2007 is calculated as the reciprocal of the sum of the thermal resistances of each layer; Fig. 7 shows this approach for Case B1.

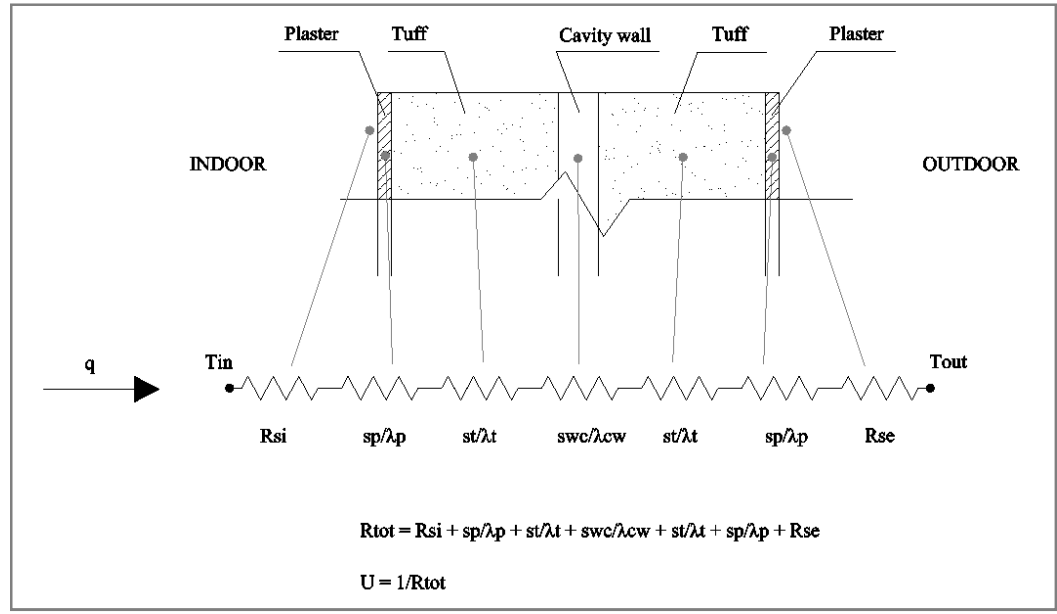

Figure 7: Calculation of U-value with standard ISO 6946:2007 for case B1.

Table 1 shows the stratigraphy of the investigated opaque elements with theoretical thermal transmittance and comparison with experimental results: very similar results are obtained, and in all cases the measured values are slightly higher than theoretical ones, 
confirming a general rule that the theoretical values generally overestimate the performance of a wall. The reasons for this are manifold: from one side, the Companies that provide components (plaster, hollow brick, etc...) tend to overestimate the performance of their products for commercial purposes and, moreover, generally the material properties are characterized in laboratory where boundary conditions (temperature and humidity) are strongly controlled; this situation diverges from environmental real conditions where temperature and humidity could not be controlled and can affect the behaviour of opaque elements.

In addition, installation work can present some irregularities which tend to deviate the real behaviour from the expected one. Lastly, the aging of the investigated walls must be considered.

For case B1, also the thermal transmittance value obtained with conventional HFM method, below described and discussed is reported.

Table 1: Opaque elements stratigraphy and comparison between thermal transmittances.

\begin{tabular}{|c|c|c|c|c|}
\hline & layers & $\mathrm{s}[\mathrm{cm}]$ & $\lambda\left[\mathrm{W} \cdot \mathrm{m} \cdot \mathrm{K}^{-1}\right]$ & $\mathrm{R}\left[\mathrm{m}^{2} \cdot \mathrm{K} \cdot \mathrm{W}^{-1}\right]$ \\
\hline \multirow{7}{*}{$\underset{\mathscr{E}}{\mathscr{\Xi}}$} & Internal surface & - & - & 0.13 \\
\hline & Plaster & 1 & 0.90 & 0.01 \\
\hline & Hollow brick & 30 & 0.43 & 0.70 \\
\hline & Plaster & 1 & 0.90 & 0.01 \\
\hline & External surface & - & - & 0.04 \\
\hline & \multirow{2}{*}{\multicolumn{4}{|c|}{$\begin{array}{l}\text { Theoretical thermal transmittance }: 1.124 \mathrm{~W} \cdot \mathrm{m}^{-2} \cdot \mathrm{K}^{-1} \\
\text { Measured thermal transmittance with modified HFM method: } 1.197 \mathrm{~W} \cdot \mathrm{m}^{-2} \cdot \mathrm{K}^{-1}\end{array}$}} \\
\hline & & & & \\
\hline \multirow{10}{*}{$\begin{array}{l}\bar{\infty} \\
\dot{\mathscr{E}} \\
\tilde{\mathscr{U}}\end{array}$} & Internal surface & - & - & 0.13 \\
\hline & Plaster & 2 & 0.90 & 0.02 \\
\hline & Tuff & 25 & 0.63 & 0.40 \\
\hline & Cavity air & - & - & 0.18 \\
\hline & Tuff & 25 & 0.63 & 0.40 \\
\hline & Plaster & 2 & 0.90 & 0.02 \\
\hline & External surface & - & - & 0.04 \\
\hline & \multirow{3}{*}{\multicolumn{4}{|c|}{$\begin{array}{l}\text { Theoretical thermal transmittance: } 0.842 \mathrm{~W} \cdot \mathrm{m} \cdot \mathrm{K}^{-1} \\
\text { Measured thermal transmittance with modified HFM method: } 0.847 \mathrm{~W} \cdot \mathrm{m}^{-2} \cdot \mathrm{K}^{-1} \\
\text { Measured thermal transmittance with conventional } \mathrm{HFM} \text { method: } 0.952 \mathrm{~W} \cdot \mathrm{m}^{-2} \cdot \mathrm{K}^{-1}\end{array}$}} \\
\hline & & & & \\
\hline & & & & \\
\hline \multirow{9}{*}{ 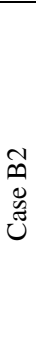 } & Internal surface & - & - & 0.13 \\
\hline & Plaster & 2 & 0.90 & 0.02 \\
\hline & Tuff & 25 & 0.63 & 0.40 \\
\hline & Cavity air & - & - & 0.18 \\
\hline & Tuff & 25 & 0.63 & 0.40 \\
\hline & Rock wool & 10 & 0.036 & 2.78 \\
\hline & Plaster & 2 & 0.90 & 0.02 \\
\hline & External surface & - & - & 0.04 \\
\hline & \multicolumn{4}{|c|}{$\begin{array}{l}\text { Theoretical thermal transmittance: } 0.252 \mathrm{~W} \cdot \mathrm{m}^{-2} \cdot \mathrm{K}^{-1} \\
\text { Measured thermal transmittance with modified } \mathrm{HFM} \text { method: } 0.326 \mathrm{~W} \cdot \mathrm{m}^{-2} \cdot \mathrm{K}^{-1}\end{array}$} \\
\hline
\end{tabular}

However, the differences between theoretical and measured thermal transmittance with modified HFM method and calculated as equation (5) are very low for Case A and $\mathrm{B}_{1}$ (respectively, $6.5 \%$ and $0.6 \%$ ), therefore lower than average values in literature (up to $16 \%$ [3, $9-12]$ or $24 \%$ [8]):

$$
\varepsilon=\frac{U_{m}-U_{t}}{U_{t}} \times 100
$$


with $U_{m}$ and $U_{t}$ were the measured and theoretical $\mathrm{U}$ values, respectively.

On the other hand, a consistent difference equal to $29.4 \%$ was observed in case B2, which can be attributed basically to large amplitude in temperature variations during the period of measurements. Indeed, contrary to the expected values shown in Fig. 3 for March, the temperature fluctuated between $2{ }^{\circ} \mathrm{C}$ and $19{ }^{\circ} \mathrm{C}$, therefore, in different moments of the measuring period, a difference of $10{ }^{\circ} \mathrm{C}$ between the two sides of the investigated wall was not achieved (Fig. 5c). Another aspect that could have affected the measurement is the noncomplete drying of the wall after the addition of the insulating layer and the plastering. Unfortunately, in this case the measures could not be performed at a later time, due to the "foreseen and not deferrable" switching off of the building air conditioning: in such a case the conditioning of the internal room would not have been made. Therefore the above mentioned two issues could not been avoided.

Nevertheless, we take into account to replicate the measurement in the next months, when issues related to drying will be overcome.

In any case, we cannot completely exclude the possibility that the performance of the thermal insulation has been overestimated; Asdrubali et al. [6] argued the same assumption when they found a difference between theoretical and experimental values of an investigated perimetral wall equal to $43 \%$, which differed a lot from other 5 cases considered in which the discrepancy range was between -14 and $+26 \%$.

At last, the investigated wall in case B2 has a thickness of $70 \mathrm{~cm}$, which is unusual when compared with the thicknesses commonly adopted.

For case B1, results obtained with our modified HFM method were compared with results obtained with conventional HFM method, performed by the Company that provided the thermal insulation. Measurements were carried out in November, with external temperatures between $14^{\circ} \mathrm{C}$ and $19^{\circ} \mathrm{C}$, while no conditioning was applied on internal room, where the temperature was in the range $19-20^{\circ} \mathrm{C}$. Therefore it is evident that the required difference of $10^{\circ} \mathrm{C}$ between the two sides of the wall was not ensured. This evidence confirms that the weather can make difficult the measurement if the conditioning of at least one side of the vertical walls is not performed.

Anyway, Fig. 8 shows temperature, heat flow and thermal transmittance trends resulting from conventional HFM measurement, from which a thermal transmittance of $0.952 \mathrm{~W} / \mathrm{m}^{2} \mathrm{~K}$ was obtained.

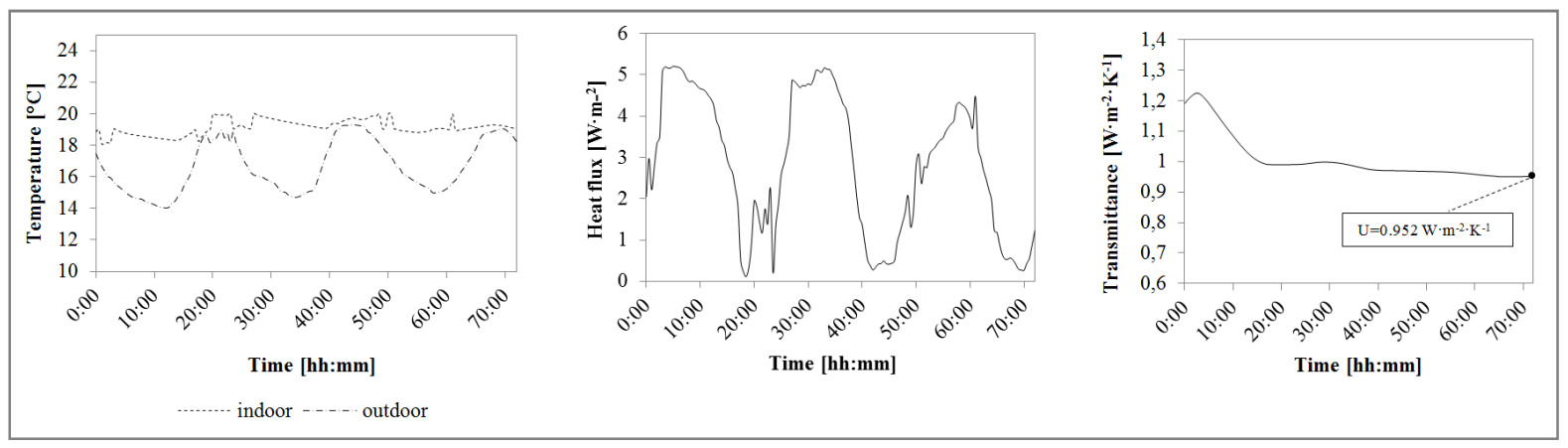

Figure 8: Temperature, heat flow and U for case B1 and with conventional HFM method .

Regardless of issues related on adequate differences in temperature between the two sides of the wall, the discrepancy with respect to the theoretical value of $0.842 \mathrm{Wm}^{-2} \mathrm{~K}^{-1}$ obtained 
from ISO 6946:2007, and calculated with equation (5), was greater of that obtained with modified HFM method ( $16.4 \%$ and $0.6 \%$, respectively).

Moreover, the amplitude of oscillations of thermal transmittance calculated in the last 24 hours in according to equation (4) was $1.95 \%$, therefore less than $5 \%$ as requested by ISO 9869-1:2014.

\section{Conclusions}

This paper refers to measuring of thermal transmittances of walls with a heat flow meter method slightly modified with respect to that described in standard reference method ISO 9869-1:2014. Main differences are based on a threefold measurement of wall temperatures and on an improved adhesion between temperature probes and wall surface, with the aim to reduce problems related to roughness and bad adhesion of surfaces. Moreover, the conditioning of at least one side of walls investigated is done, to assure the required difference in temperature between internal and external sides (at least $10^{\circ} \mathrm{C}$ ), which otherwise would not be ensured in the Mediterranean areas, to which this paper refers. This last aspect is particularly important also from a bureaucratic point of view: indeed, in terms of energy upgrading of buildings, the Apulia Region may provide that a feasibility study that includes the transmittance measurement of the vertical walls must be completed within 30 working days from the assignment of a contract. If within this period changings in weather conditions makes difficult the measurement, the feasibility study would be compromised. Clearly, the conditioning of walls helps to get rid from this issue.

The modified HFM method was applied on three cases: an internal wall and a perimetral wall before and after the introduction of an outer insulating layer (rock wool). Results obtained were compared to theoretical U-values obtained with ISO 6946:2007, and also with standard HFM method in case of the perimetral wall without insulating layer. Main results are hereinafter summarized:

- the differences between U-values obtained with the modified HFM method and theoretical ones were in the range $0.6-6.5 \%$ for cases in which no high fluctuations in temperatures were observed.

- the difference between U-value obtained with the modified HFM method and theoretical one was $29.4 \%$ for perimetral wall with insulating layer, in which high fluctuations in external temperature was observed.

- The measurements performed on the perimetral wall and after the conditioning of the internal rooms (heating or cooling) assured a difference in temperature wall surface between internal and external sides of at least $10^{\circ} \mathrm{C}$. This was not assured when the conditioning of internal room was not performed. This aspect confirms that the conditioning of rooms can resolve the problem related to variability of weather conditions that may affect the measurements.

- The modified HFM method provided a result closer to the theoretical one, when compared to that obtained with the standard HFM method (discrepancy with theoretical value were $0.6 \%$ and $16.4 \%$, respectively).

- In all the measurements performed, the amplitude of the thermal transmittance oscillations, calculated in the last 24 hours, were less than $5 \%$ as requested by the ISO 9869-1:2014. 


\section{Acknowledgement}

This work was supported by EFFEDIL Project (EFFicient Energy builDing Innovative soLutions, Grant number: PON02_00323_2938699) funded by Italian Ministry of Education and Research. The authors of the present work thank:

i. the Department of Engineering of Politecnico di Bari for having made available the room for case A;

ii. the High School and municipal authority of Mesagne for having permitted the investigation of case B1 and B2;

iii. Mr. Mengoli Paolo, engineer of Company which provided the thermal insulation, for performing measurement with conventional HFM method in case B1;

iv. Mr. Raimondo Luca and Mr. Alessandro Politi, architects, for the helpful contribution on setting the measurement operative mode and for the fruitful discussion about the topics of this paper;

v. Mr. Massaro Marcello of ENEA for the preparation of the equipment in measurements with modified HFM method in case B1 and B2.

\section{References}

[1] ISO Standards. (2007). Building components and building elements - Thermal resistance and thermal transmittance - Calculation method. ISO6946:2007. Geneva (Switzerland).

[2] ISO Standard. (2014). Thermal insulation - Building elements - In-situ measurement of thermal resistance and thermal transmittance - Part 1: Heat flow meter method. ISO9869-1:2014. Geneva (Switzerland).

[3] Feuermann, D. (1989). Measurement of envelope thermal transmittances in multifamily buildings. Energy and Buildings, 13(2), 139-148. doi:10.1016/03787788(89)90005-4.

[4] Mumaw, J.R. (1974). Calibrated Hot box: An effective means for measuring thermal conductance in large wall sections. In R.P. Tye (Eds.), Heat transmission measurements in thermal insulations (pp. 193-211). Philadelphia: ASTM.

[5] Mumaw J.R., (1980). Thermal research facility - A large calibrated hot box for horizontal building elements. In D.L. McElroy, R.P. Tye (Eds). Thermal insulation performance (pp. 195-207). West Conshohocken, PA: ASTM.

[6] Asdrubali, F., D'Alessandro, F. \& Baldinelli G. (2014). Evaluating in situ thermal transmittance of green buildings masonries - A case study. Case studies in Construction Materials 1, 53-59. doi:10.1016/j.cscm.2014.04.004.

[7] Ahmad, A., Maslehuddin, M. \& Al-Hadhrami, L.M., (2014). In situ measurement of thermal transmittance and thermal resistance of hollow reinforced precast concrete walls. Energy and Buildings 84, 132-141. doi:10.1016/j.enbuild.2014.07.048. 
[8] Peng, C. \& Wu, Z. (2008). In situ measuring and evaluating the thermal resistance of building construction. Energy and Buildings 40(11), 2076-2082. doi:10.1016/j.enbuild.2008.05.012.

[9] Trethowen, H. (1986). Measurement errors with surface-mounted heat flux sensor. Building and Environment 21(1), 41-56. doi:10.1016/0360-1323(86)90007-7.

[10] American Society for Testing and Materials. (2000). Standard test method for steadystate heat flux measurements and thermal transmission properties by means of the guarded-hot-plate apparatus. ASTMC 177-97. West Conshohocken, PA.

[11] American Society for Testing and Materials. (2001). Standard test method for steadystate thermal performance of building assemblies by means of a guarded hot box. ASTM C236-89. West Conshohocken, PA.

[12] Desogus, G., Mura, S. \& Ricciu, R. (2011). Comparing different approaches to in situ measurement of building components thermal resistance. Energy and Buildings 43(10), 2613 - 2620. doi:10.1016/j.enbuild.2011.05.025.

[13] Meng, X., Yan, B., Gao, Y., Wang, J., Zhang, W. \& Long, E. (2015). Factors affecting the in situ measurement accuracy of the wall heat transfer coefficient using the heat flow meter method. Energy and Buildings 86, 754-765. doi:10.1016/j.enbuild.2014.11.005.

[14] ISO Standard. (1983). Thermal insulation - Qualitative detection of thermal irregularities in building envelopes - Infrared method. ISO 6781:1983. Geneva (Switzerland).

[15] ISO Standard (1991). Thermal insulation - Determination of steady-state thermal resistance and related properties - Heat flow meter apparatus. ISO 8301:1991. Geneva (Switzerland).

[16] Peel, M.C., Finlayson, B.L. \& McMahon, T.A. (2007). Updated world map of the Köppen-Geiger climate classification. Hydrol. Earth Syst. Sci. 11(5), 1633-1644. doi:10.5194/hess-11-1633-2007.

[17] ENEA Climate Archive. (2016). Average recorded temperature and relative humidity in Bari. Retrieved June 12, 2016 from

http://clisun.casaccia.enea.it/Profili/tabelle/548\%20\%5BBari\%5D\%20capoluogo.Txt. 